\title{
MONITORING THE THREAT OF SINKHOLE FORMATION UNDER A PORTION OF US 18 IN CERRO GORDO COUNTY, IOWA USING TDR MEASUREMENTS
}

Kevin M. O'Connor

GeoTDR, Inc., 720 Greencrest Drive, Westerville,Ohio 43081 koconnor@gci2000.com

\section{Matthew Trainum}

Office of Design, Soils Design Section, Iowa Department of Transportation, 800 Lincoln Way, Ames, Iowa 50010 Matthew.Trainum@dot.iowa.gov

\section{Abstract}

Sinkhole formation is a common occurrence in northeast Iowa, and US 18 in Cerro Gordo County was constructed over an area where sinkhole formation had only been locally known. It had not been recorded or identified in the Iowa DNR database at the time. Since 2004, sinkholes have developed along the right of way. Geophysical surveys contributed very little in the identifying the cause. However a Soil Survey (drilling program) identified numerous voids within carbonate bedrock. The soil borings indicated that shale overlying the carbonate rock has been removed/ eroded, and resulted in the development of a karst subsurface through the dissolution of the carbonate rock. Without removing the structural fill and site soils to expose the rock, it will not be possible to impede the natural processes occurring. An alternative approach was adopted and consisted of: (a) removing the existing pavement, (b) installing coaxial cables in trenches excavated within the subgrade, (c) replacing the pavement as double reinforced pavement (including shoulders), and (d) monitoring the cables using Time Domain Reflectometry (TDR). The cables are interrogated several times a day and data is transmitted via cellular modem to Iowa DOT facilities. Among the data transmitted is a log file of deformation activity along each of the cables which is evaluated and an action plan is initiated based on: (a) information in the activity file, and (b) updated plots for each cable. Unexpected behavior has been observed, with activity occurring annually between the months of September and March. Although several explanations have been proposed, there is no definitive correlation between locations of the activity detected by TDR, sinkhole locations, or geophysical anomaly locations. In spite of this uncertainty, real time remote monitoring for ground movement is continuing.

\section{Background}

In 2004, several sinkholes formed along US 18 between STA 248+00 and 250+00 (distance of 200 $\mathrm{m}$ or 600 feet). A couple of sinkholes formed on the shoulders of the eastbound lane (Figure 1 and Figure 2). In addition, several small sinkholes and one rather large sinkhole formed in the ditch of the eastbound lane. A geophysical investigation, to determine the cause and extent of the problem (and propose options for remediation) included a Ground Penetrating Radar Survey, a Resistivity Survey, and a Soil Survey (drilling program). No voids were identified beneath or within a couple meters of the pavement surface. It was decided to continue to monitor the area for sinkhole formation and to investigate the integrity of the roadway should additional sinkholes form within the limits of the area of concern (Figure 3 STA $248+00$ to $253+00,500 \mathrm{~m}$ or 1500 feet), as determined by a geologic review and analysis of the drilling data. In addition, as a remediation to the problem, a double reinforced inlay or overlay was proposed for the area of concern, as soon as it became practical.

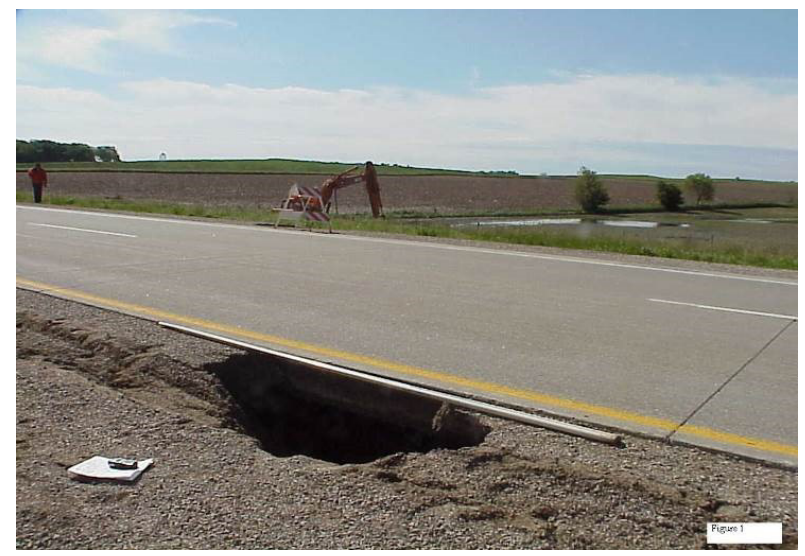

Figure 1. Sinkhole that developed in the north shoulder of the eastbound lane. 


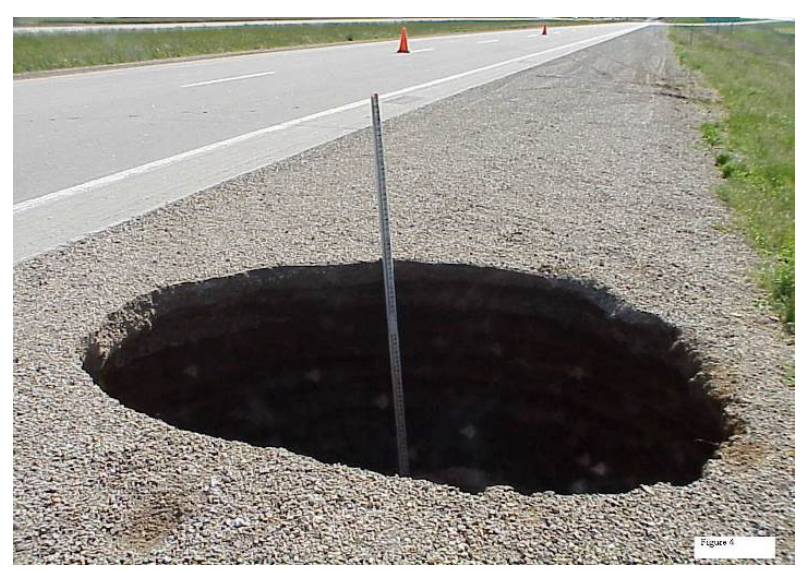

Figure 2. Sinkhole that developed in the south shoulder of the eastbound lane.

In 2005, a sinkhole developed at STA 249+30 just outside the Right of Way and within the limits of the area of concern (Figure 3). An investigation of the immediate area below the roadway included Ground Penetrating Radar (GPR) and Multi-Channel Analysis of Surface Waves (MASW). No voids were identified immediately beneath the pavement, or within a depth of a couple of meters beneath the pavement surface.
In 2008, a large sinkhole formed within the EB ditch at STA $251+50$, east of the previous sinkholes and within the area of concern. An investigation of the immediate area below the roadway included only Ground Penetrating Radar. No voids were identified beneath or within a couple meters of the pavement surface.

In 2009, a project was designed for letting that would install a double reinforced inlay, including shoulders, for the designated area of concern. In addition to the inlay, the installation of a Time Domain Reflectometry (TDR) System was chosen as a device for real-time monitoring of the formation of voids/sinkholes under the roadway.

\section{Site Conditions and Regional Setting}

Karst refers to geologic, hydrologic, and landscape features associated with the dissolution of soluble rocks, such as carbonates and evaporites. A common feature of karst landscapes are sinkholes, which form when the land surface collapses into subsurface voids formed in the slowly dissolving rock. In Iowa, carbonate rocks are the common bedrock throughout the state, and are

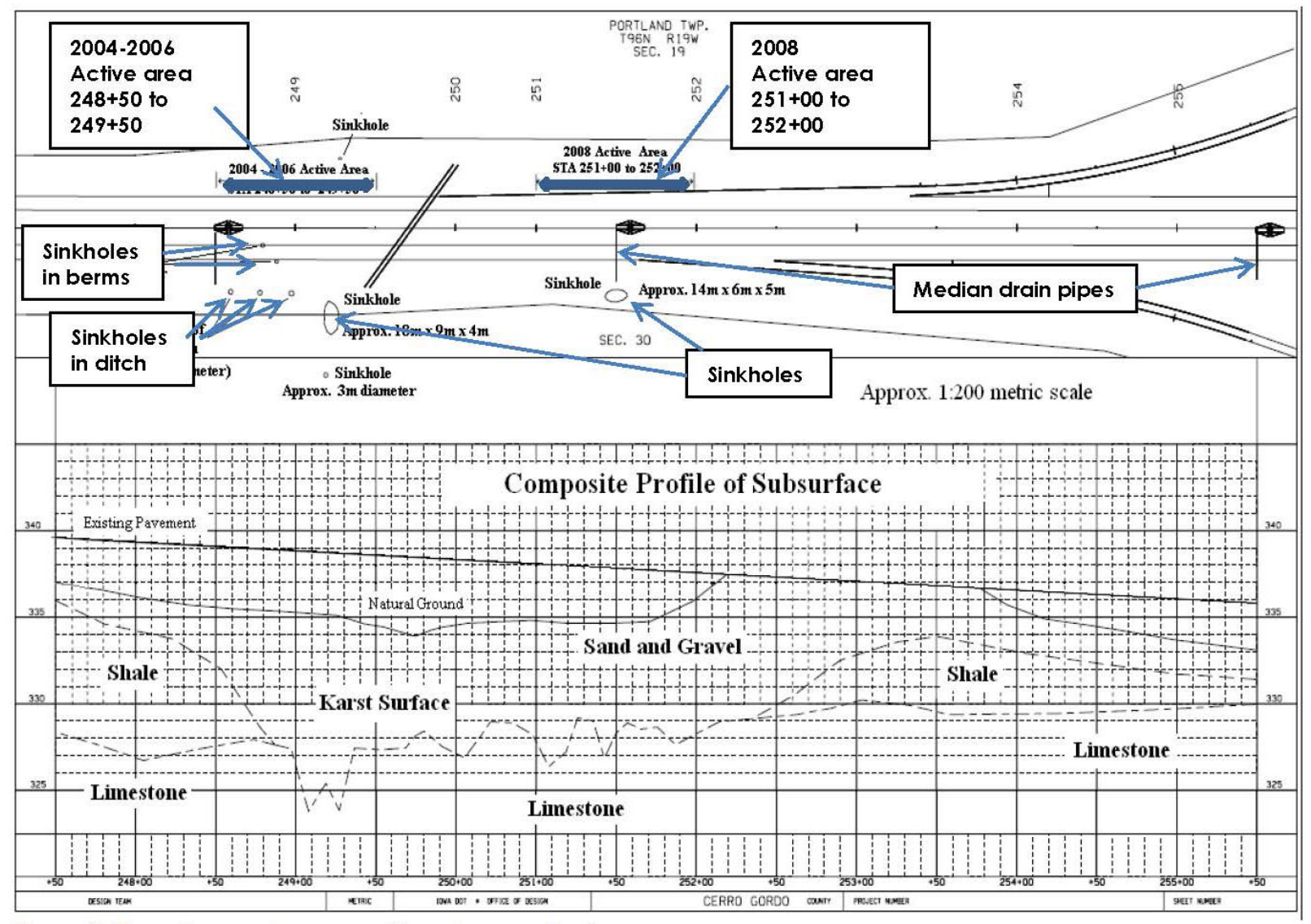

Figure 3. Plan view and cross section along project area. 
mantled with a variable thickness of glacial and other unconsolidated materials. Where these unconsolidated materials are less than $15 \mathrm{~m}$ (50 feet), and particularly less than $7 \mathrm{~m}$ thick (25 feet), sinkholes may occur. There are three areas in Iowa where large numbers of sinkholes exist (Figure 4): (1) within the outcrop belt of the Ordovician Galena Group carbonates in Allamakee, Clayton, and Winneshiek counties; (2) in Devonian carbonates in Bremer, Butler, Chickasaw, and particularly Floyd and Mitchell counties; and (3) along the erosional edge of Silurian carbonates in Dubuque and Clayton counties (Halberg and Hoyer, 1982).

The site is along US 18 in Cerro County between C.R. S56 and US 65 south of Mason City near Floyd County (Figure 4). There is structural fill over natural sand and

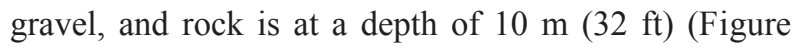
3 ). The geological interpretation of the subsurface below the area of concern (a 450 to 500 meter, or 1200 to 1600 feet, stretch of roadway) is that a buried streambed or glacial trough exposed the carbonate bedrock which has since been undergoing karst dissolution. There is shale overlying the carbonate rock east and west of the area (Figure 3).

\section{Fractures and Voids in Rock}

In response to the development of sinkholes (Figures 1 and 2), borings were performed by Iowa DOT in 2004 which located voids in the limestone rock underlying natural sand and gravel soils (Figure 3). Soil piping, a process of transporting material out of the soil column and into voids within the carbonate bedrock, is the assumed cause for the sinkholes. The voids are assumed to be locations where fractures in the rock have become enlarged.

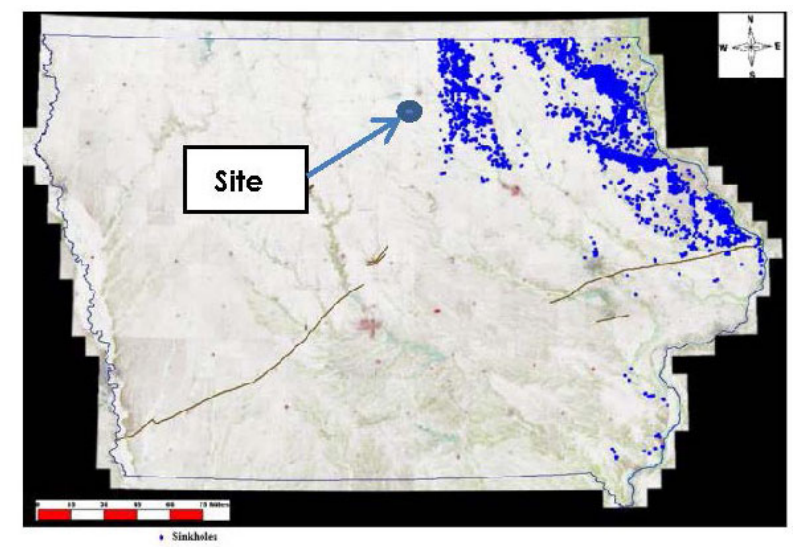

Figure 4. lowa statewide sinkholes mapped. Site location indicated by solid circle, and Floyd County is east of site.

\section{Sinkhole Development and Precipitation Events}

Sinkhole locations (Figure 3) correlate with locations of median drain pipes and arched pipe culverts below US 18 (Figure 5). The drain pipes at median dikes direct flow to the south side of US18, and the arched pipe culverts direct flow from south to north along a preexisting swale. Surface runoff is concentrated by the median drain pipes and preexisting swale to locations where sinkholes have developed. Major precipitation events occurred in May 2004 and in May/June 2008 (Buchmiller and Eash, 2010). It was during these periods when sinkholes developed.

\section{Geophysical Survey and Anomalies}

A geophysical survey was performed in 2005 using GPR and MASW. Anomalies were typically at depths less than $1 \mathrm{~m}$ and were mostly attributed to variations within the structural fill. Drilling to provide confirmation did not identify anything to account for the anomalies.

While there has been a variety of geophysical data obtained at this site, the focus of this paper is upon TDR measurements.

\section{TDR System Design and Installation}

The TDR system was designed to minimize disturbance of the subgrade after removal of the existing pavement, but provide early warning if sinkhole development occurs below the new double-reinforced pavement. Coaxial cables were installed in trenches at a depth of $1 \mathrm{~m}$, and redundancy is provided by two trenches below each lane (Figure 5).

As shown in Figures 6 and 7, the existing pavement was removed and trenches were excavated. Two trenches, $0.5 \mathrm{~m}$ left and right of centerline under each lane were excavated to a depth of 1 meter (for a total of eight cables). The $22 \mathrm{~mm}$ diameter solid aluminum coaxial cable was laid out and crimped at a spacing of $15 \mathrm{~m}$ (50 feet) as shown in Figure 8 and 9. Larger crimps were made at either end of the monitoring zone (STA 252+65 and STA $248+00$ ). After placing the cable in each trench (Figure 10 ), cement grout was placed over the cable (Figure 10 and 11) so that in the event of sinkhole formation, the grout will fracture and cause deformation of the metallic cable. The grout has a compressive strength of approximately $200 \mathrm{psi}$ (compared with concrete which has a compressive strength of $3000 \mathrm{psi}$ ). The trench was then backfilled by compacting excavated soils, and the new pavement was installed. 


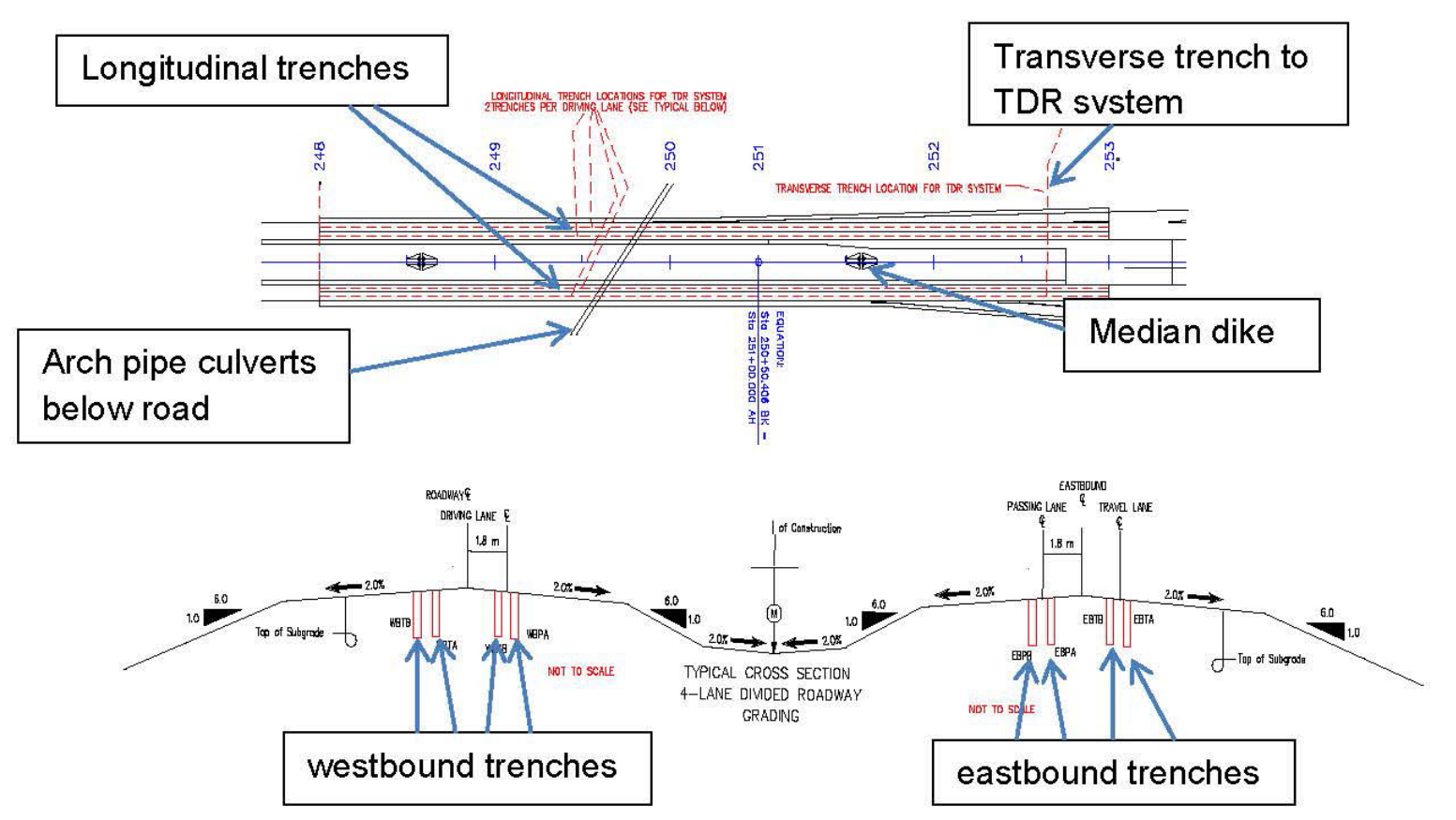

Figure 5. Layout of trenches with coaxial cable.

\section{TDR Monitoring}

A TDR unit (Figure 12) launches a voltage pulse along a cable. Wherever the cable has been deformed a portion of the pulse is reflected back to the TDR unit, which converts travel time into distance. The magnitude and type of reflection is indicative of the magnitude and type of cable deformation. Consequently, the data identifies each location where the cable is being deformed and, in the case where a cable is being subjected to localized shear, the reflection magnitude is proportional to the magnitude of cable deformation (O'Connor and Dowding, 1999).

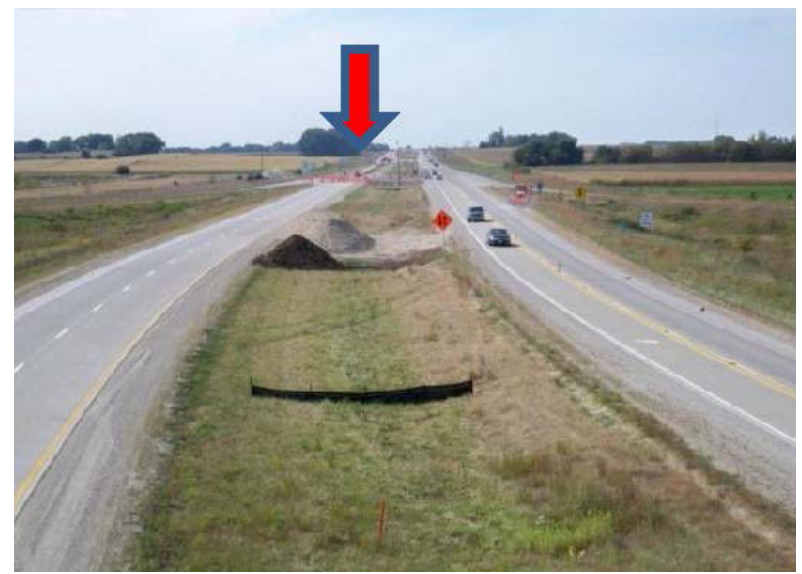

Figure 6. View looking west at area where pavement is being removed from eastbound lanes.

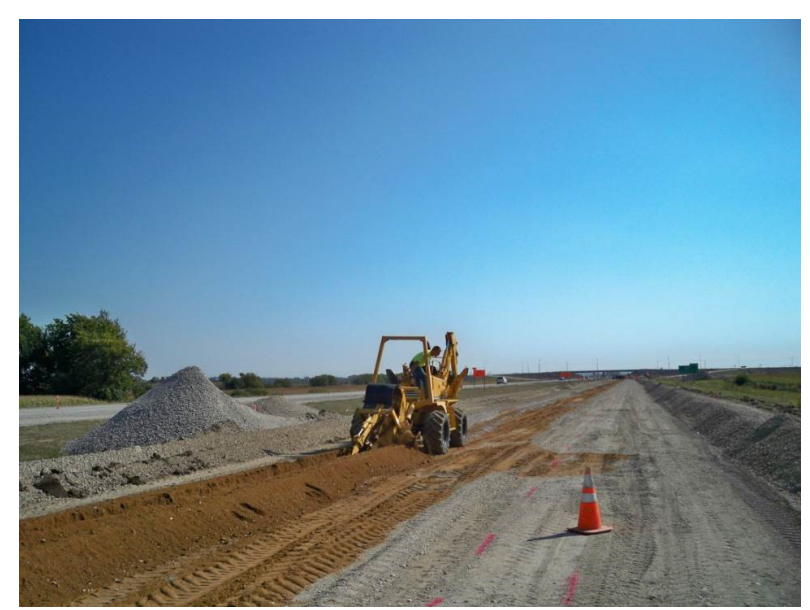

Figure 7. One of the two trenches being excavated below the eastbound passing lane.

The data acquisition system (DAS) consists of a programmable datalogger, TDR unit, coaxial multiplexer, and wireless modem (Figure 13 and 14). The datalogger controls the TDR and multiplexer and switches channels so that each cable is interrogated at specified times. The datalogger stores the acquired digital TDR waveform and the data points are then downloaded via wireless modem to Iowa DOT facilities.

The most common approach for monitoring ground movement using TDR technology is to compare current 


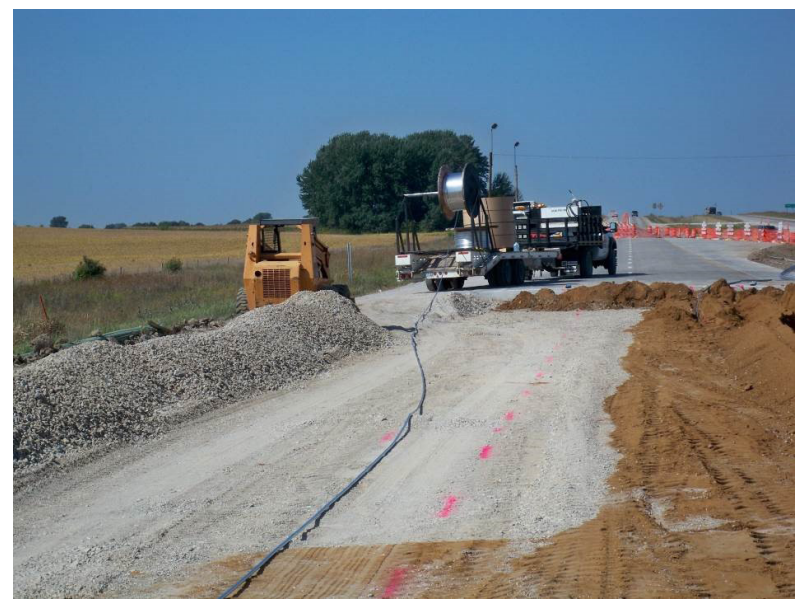

Figure 8. Coaxial cable laid out for crimping prior to placement in trench.

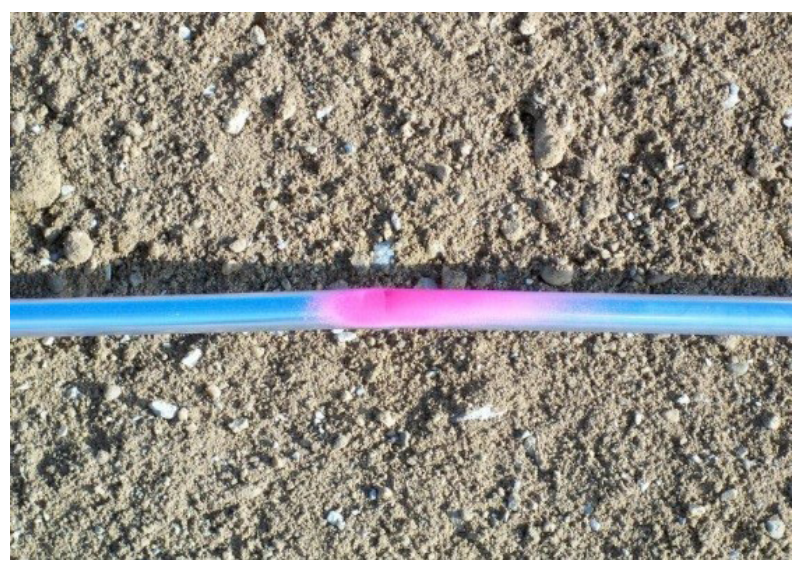

Figure 9. Crimp in coaxial cable.

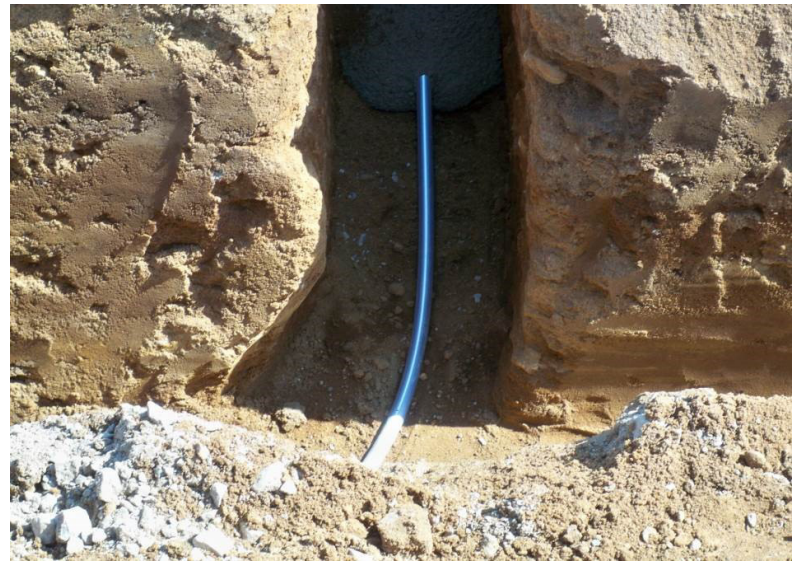

Figure 10. Coaxial cable placed in trench.

waveforms with baseline waveforms and wherever the difference between these two readings exceeds predetermined criteria, an alarm flag is raised and project personnel are notified by the monitoring system. This approach was being used effectively during the period from April 2010 until September 2011. However,

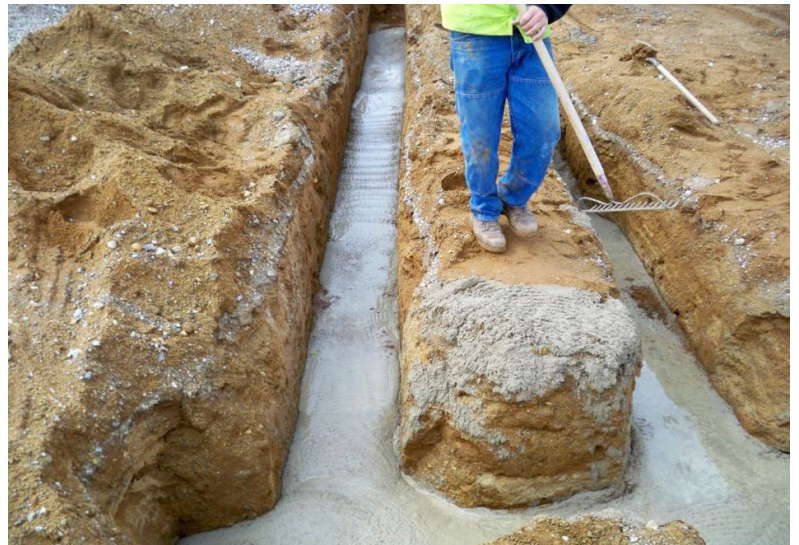

Figure 11. Grout being placed over cable.

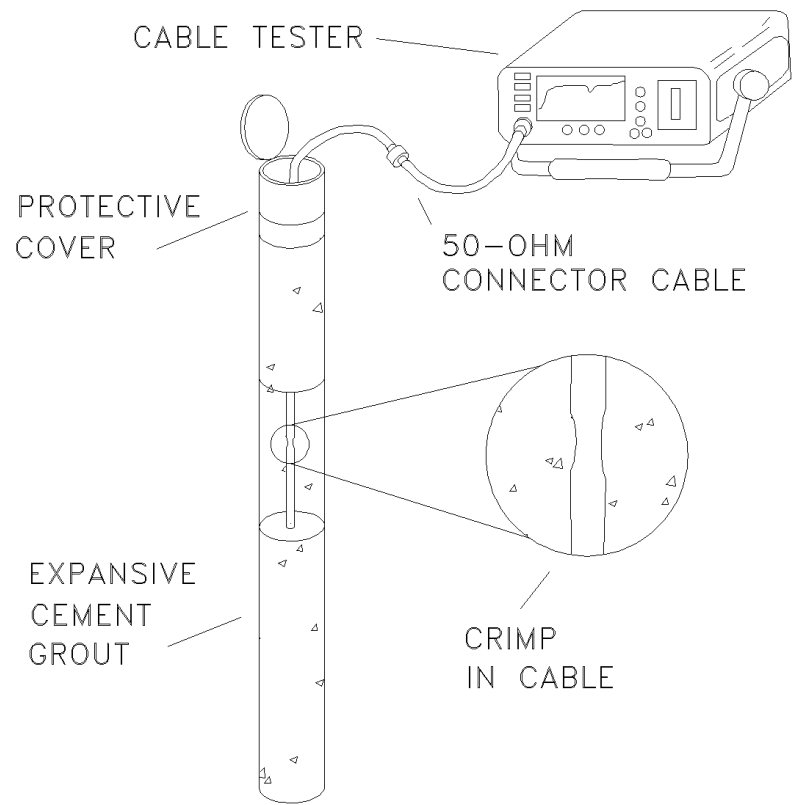

Figure 12. Schematic of TDR cable installation.

unexpected waveforms (discussed below) and the inability to explain their cause created significant skepticism. Furthermore, it created reluctance to implement the automated monitoring and email notification capabilities.

As a consequence, it was necessary to modify the algorithm used to monitor cable deformation, and also the algorithm used to initiate email notification to project personnel. These are now treated as separate functions of the monitoring system.

The TDR system will send out an Initial Notification or "alert" when it has detected cable deformation that meets alert levels based on criteria programmed into 


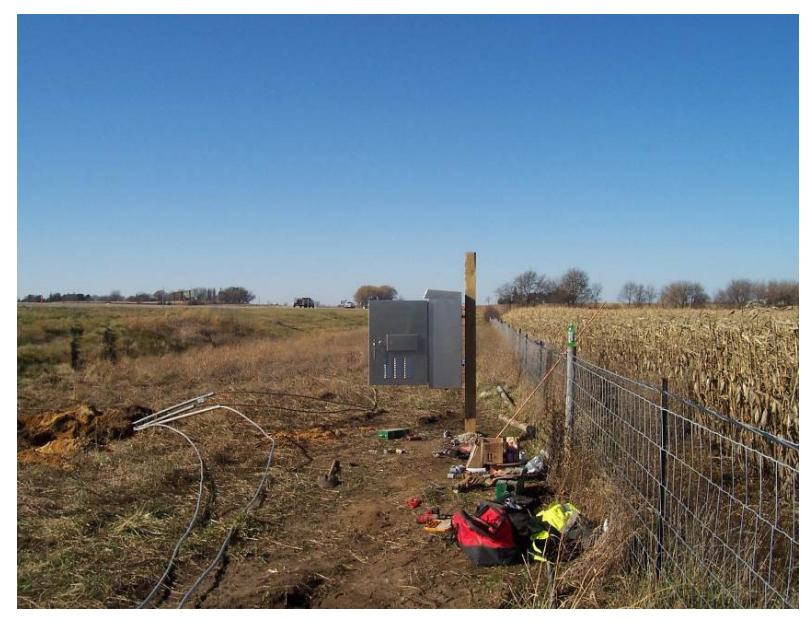

Figure 13. Head end of cables prior to placement in conduit into DAS enclosure.

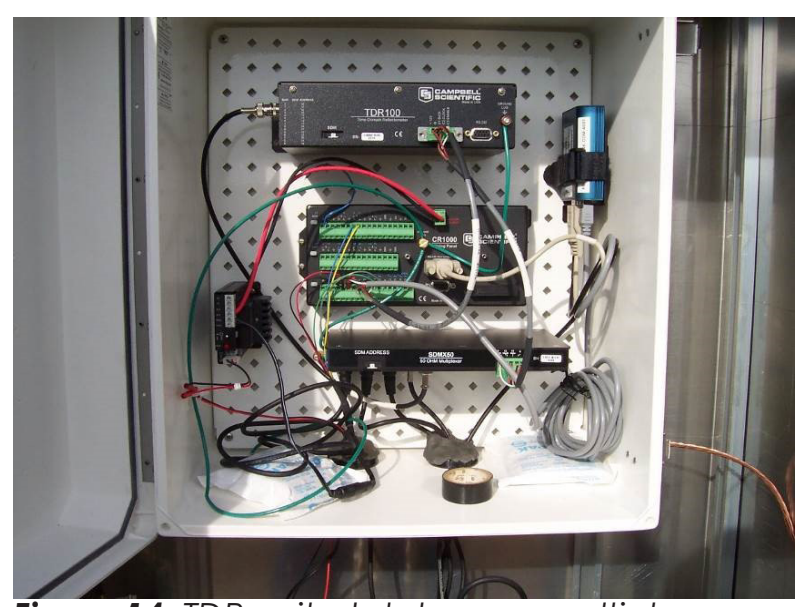

Figure 14. TDR unit, datalogger, multiplexer, and wireless modem in DAS.

the datalogger. Alerts are in the form of emails and text messages. The DOT Operation Support Center, Highway Maintenance Supervisor, District Operations Manager, District Maintenance Manager, District Engineer, Soils Design Geologists, and Soils Design Engineers receive a direct Initial Notification. An Initial Notification indicates the cable along which the activity occurred and directs the recipients to the Activity Log File (TDR data). After an on-site investigation, and review/ evaluation of the TDR data, the Soils Design Section of the Office of Design will issue a Second Notification either confirming or dismissing the Initial Notification. Dismissals, confirmations, and any further definition of an alert, by categorizing the level of the alert, are based on the review and evaluation, the interpretation of TDR data files and activity logs, and additional criteria.

\section{TDR Activity}

There have been thirty-three (33) events detected as summarized in Table 1. Thirty (30) events have occurred under the roadway. Fifteen (15) of the events under the roadway are located between STA $249+50$ and STA $250+00$ in the vicinity of the two arched pipes (Figure 5). The TDR activity in the vicinity of the two pipes has persisted from Sept 2011 to the present.

In November 2011 and January 2012, exploratory pavement core drilling was performed in the westbound lanes at STA $249+72$, STA $249+75$, and STA $249+78$, but did not find evidence of subsurface movement between the pavement and subgrade, and GPR surveys in the westbound lanes from STA 249+00 to STA 250+50, and through the arched pipe culverts (see Figure 5) did not find any voids.

Table 1a. Summary of TDR Activity.

\begin{tabular}{|c|c|c|c|}
\hline Cable & Station & Date Initiated & \multirow{5}{*}{$\begin{array}{l}\mathrm{EBTA}=\text { eastbound travel lane } \\
\text { trench A } \\
\text { EBTB = eastbound travel lane } \\
\text { trench B } \\
\text { EBPA = eastbound passing lane } \\
\text { trench A } \\
\text { EBPB = eastbound passing } \\
\text { lane trench B }\end{array}$} \\
\hline EBTA & $\begin{array}{l}248+08 \\
248+75 \\
249+29 \\
249+68 \\
250+37 \\
\end{array}$ & $\begin{array}{l}\text { Nov } 2012 \\
\text { Jan } 2014 \\
\text { Jan } 2014 \\
\text { Jan } 2014 \\
\text { Nov } 2014\end{array}$ & \\
\hline EBTB & $\begin{array}{l}248+00 \\
249+57 \\
249+69 \\
249+80 \\
250+50 \\
\end{array}$ & $\begin{array}{l}\text { Dec } 2011 \\
\text { Nov } 2013 \\
\text { Jan } 2013 \\
\text { Mar } 2014 \\
\text { Mar } 2014 \\
\end{array}$ & \\
\hline EBPA & $\begin{array}{l}248+00 \\
249+30\end{array}$ & $\begin{array}{l}\text { Dec } 2011 \\
\text { Oct } 2014\end{array}$ & \\
\hline EBPB & $\begin{array}{l}248+00 \\
249+51 \\
250+09 \\
251+56\end{array}$ & $\begin{array}{l}\text { Dec } 2011 \\
\text { Jan } 2013 \\
\text { Nov } 2014 \\
\text { Nov } 2014\end{array}$ & \\
\hline
\end{tabular}

Table 1b. Summary of TDR Activity.

\begin{tabular}{|l|l|l|}
\hline Cable & Station & $\begin{array}{l}\text { Date } \\
\text { Initiated }\end{array}$ \\
\hline WBPA & $248+24$ & Jan 2014 \\
& $248+63$ & Jan 2014 \\
& $248+88$ & Nov 2012 \\
& $249+77$ & Jan 2015 \\
\hline WBPB & $251+86$ & Dec 2014 \\
\hline WBTA & $249+69$ & Sept 2011 \\
& $249+77$ & Sept 2011 \\
& $249+83$ & Sept 2011 \\
& $249+89$ & Sept 2011 \\
& $249+95$ & Sept 2011 \\
& $251+27$ & Jan 2014 \\
& $251+67$ & Dec 2014 \\
\hline WBTB & $249+86$ & Nov 2012 \\
& $249+93$ & Nov 2014 \\
& $251+42$ & Feb 2014 \\
& $251+60$ & Nov 2012 \\
& $251+87$ & Jan 2015 \\
\hline
\end{tabular}

WBPA $=$ westbound passing lane trench $\mathrm{A}$

$\mathrm{WBPB}=$ westbound passing lane trench B

WBTA $=$ westbound travel lane trench A

WBTB $=$ westbound travel lane trench B 
Obviously, the TDR activity has been generated by some mechanism other than ground movement and void formation that would occur if sinkholes were developing under the roadway.

\section{Discussion}

The premise for installation of the TDR system was monitoring of the development of sinkholes beneath US 18 between STA $248+00$ and $252+60$. Based on experience, it is anticipated that the grouted coaxial cables will be subjected to localized shear as the ground moves.

Beginning in September 2011, waveforms were being acquired that were not consistent with the expected cable deformation. When cables are deformed due to ground movement, distinct negative spikes develop in the TDR waveform due to reflections from these locations of cable deformation (Figure 16). The reflections that have developed are more characteristic of cable abrasion (Figure 17) rather than cable deformation.

When ground movement occurs, the grout is fractured and localized deformation of the cable begins. For example, during installation of the cables, crimps were made at a spacing of $15 \mathrm{~m}$ to provide distance references in the TDR waveform. These crimps provide distinct negative spikes in the waveform (see Figure 16). This is the type of reflection that develops when ground movement causes shear deformation of the cable.
The reflections that have developed are not indicative of cable shear or tensile deformation due to ground movement. The reflections which have developed in disparate locations along cables are associated with an inductive type of cable fault (see Figure 17). This type of fault is typically due to abrasion of the outer conductor of the coaxial cable.

The TDR reflections have been persistent, and have occurred in each of the eight cables (see Figure 18 for the cable installed in a trench under the eastbound travel lane). In addition to the unexpected TDR reflections that began developing in September 2011, there have been periods of intermittent reflections along cable. These intermittent reflections are common, and they are not associated with cable deformation. The unexpected reflections and the intermittent reflections were large, and extended over long portions of the TDR records. These created false alarms, and raised questions as to the validity of information being provided.

In Figure 15, locations of sinkholes, geophysical anomalies, voids in rock (based on drilling), and TDR activity are plotted. There are a few locations (EB STA 248+75, EB STA 249+29, EB STA 251+56, and WB STA 248+63) where there is some correlation. However, there are many other locations where persistent TDR activity has been recorded but there is no correlation with evidence of sinkhole locations.

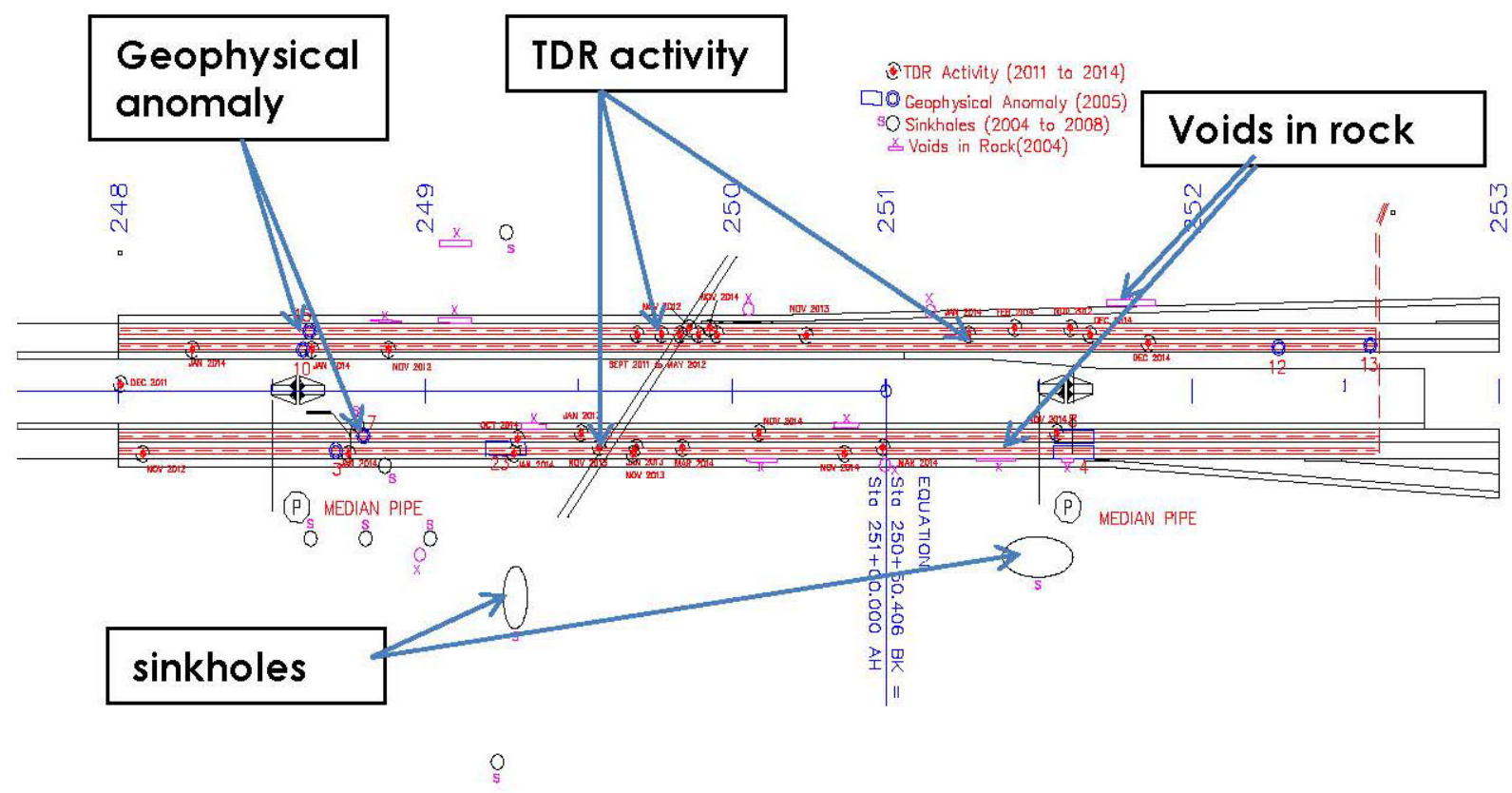

Figure 15. Overview of sinkhole locations, geophysical anomaly locations, and TDR activity locations. 


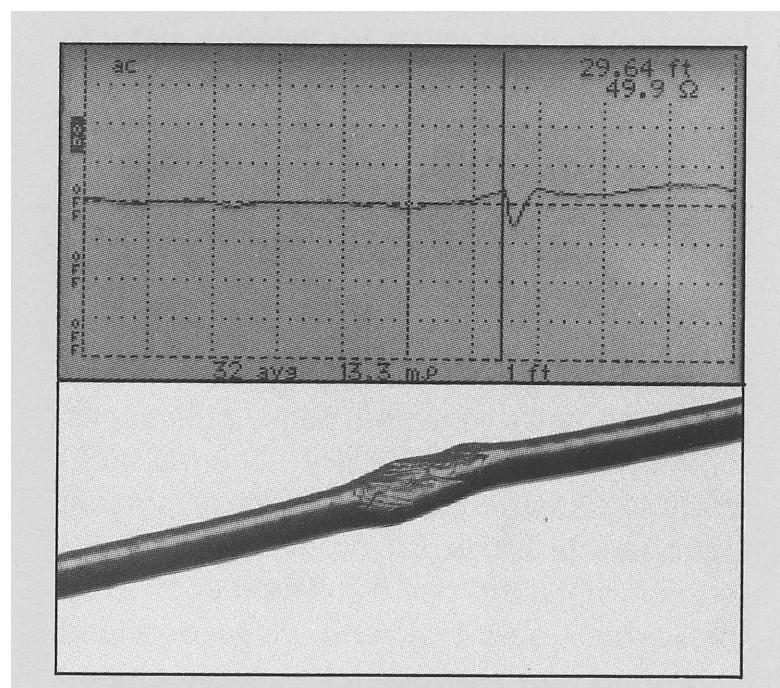

Figure 16. TDR waveform for crimp in cable (Tektronix, 1989).

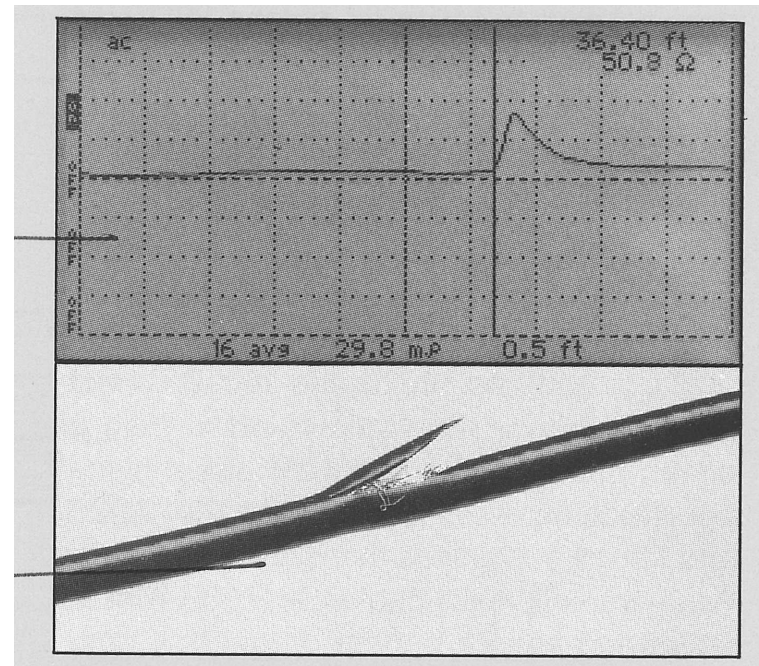

Figure 17. TDR waveform for abraided cable (Tektronix, 1989).

\section{Assessment of Anomalous TDR Response}

It has been possible to replicate the inductive type of TDR reflections. Using bench scale tests in the laboratory in which the outer conductor was progressively abraided, it is possible to produce the large positive TDR reflections such as those that have developed. There are several possible explanations as to the type of cable damage that is occurring which would generate these reflections.

\section{Cable Deformation Due to Ground Movement}

Ground movement is a conceivable mechanism. Ground movement due to sinkhole formation would cause fracture of the grout in tension and continued movement would pull the cable through the grout which could abraid the cables. In addition, TDR reflections indicative of cable crimping or shear have developed in the adjacent cables under the westbound travel lane at WBTB STA 249+86 and WBTA STA 249+69 (Table 1b).

\section{Cable Deformation Due to Shrinkage of Soils or Grout Shrinkage}

There has been an ongoing drought, and soil shrinkage is a possible mechanism. This theory would be supported by the fact that moisture is not entering cables at the abraided areas. This theory would require soil shrinkage sufficient to locally fracture the grout in tension and then continued shrinkage to pull the cable through the grout in order to abraid the cable. Similarly, shrinkage of grout could cause cracking, and then continued shrinkage could cause the cable to be pulled through the grout.

\section{Cable Deformation Due to Frost Heave}

Similar to soil shrinkage, frost heave could cause tensile fracture of the grout and continued heave could pull cables through the grout. However, the timing when the TDR reflections developed does not entirely coincide with the period when frost would be deepest which would likely rule out frost heave.

\section{Cable Deformation Due to Gnawing Animals}

The TDR traces are consistent with those obtained from cables where squirrels have gnawed the outer aluminum conductor (Cook, 2013). In addition, the development of sinkholes on either side of the eastbound lanes in 2004 is similar to those which have been created by burrowing animals (Barsness, 2011). Common burrowing mammals in the area include foxes, skunks, groundhogs, and

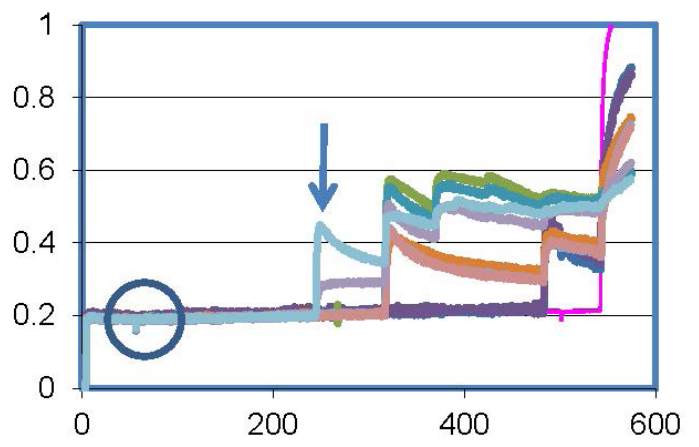

Figure 18. TDR waveforms for the cable installed in eastbound travel lane trench A. Reflection from crimp at $56 \mathrm{~m}$ is circled. Reflection from abrasion at $245 \mathrm{~m}$ is indicated with arrow. Left axis is dimensionless reflection coefficient in rho. 
gophers (Lorena. 2010). To assess this scenario, the site was visited by IDOT and IDNR personnel. One burrow entrance was located, but not near locations where TDR reflections have developed along the coaxial cables.

While these TDR reflections are not indicative of cable deformation due to ground movement, they could be precursor indications (e.g., collapse of large burrows).

\section{Summary}

Sinkholes have developed along US 18 in Cerro Gordo County where karst dissolution of carbonate rock is occurring in an area where overlying shale is missing. Soil piping of overlying soil material into voids that formed/enlarged along fractures is the assumed process for sinkhole formation.

Coaxial cables were installed in trenches beneath the roadway to monitor ground movement associated with sinkhole formation. TDR activity has developed in 2011, 2012, 2013, and 2014. This activity has been initiated each year during the period from October to January, and predominantly in November. Although activity has been detected in each of the eight coaxial cables, there is no definitive correlation between TDR activity locations, sinkhole locations, or geophysical anomaly locations.

Several explanations have been proposed for the activity, and based on the TDR waveforms, one possibility is that burrowing animals are gnawing on the cable. However, there is very limited evidence of animal burrowing.

The effectiveness of TDR measurements has been clearly demonstrated (O'Connor and Dowding, 1999). However, sometimes we encounter situations in which some of the data and its interpretation are not clear.

In spite of the uncertainty with regard to TDR activity to date, if ground movement impacts the coaxial cable the resultant cable deformation will be detected. The threshold for notifications is high enough that if it is reached the most likely cause is the deformation and breaking of the cable, which would result from the formation of a significant void/sinkhole beneath the pavement. Consequently, the primary objective of monitoring for voids/ sinkholes developing beneath the reinforced pavement is being achieved.

\section{References}

Barsness S, 2011 December 19. Lake Sammamish beaver invasion: parks and city struggle to balance nature and community needs. Issaquah-Reporter. Available from: http://www.issaquahreporter.com/ news/97672974.html.

Buchmiller RC, Eash DA. 2010. Floods of May and June 2008 in Iowa. USGS Open-File Report 2010-1096. Available from: http://pubs.usgs.gov/ of/2010/1096/pdf/OFR2010-1096.pdf.

Cook T. 2013. Personal communication. Director of Global Engineering, Times Fiber Communications, Inc.

Halberg GR, Hoyer BE. 1982. Sinkholes, hydrogeology, and groundwater quality in northeast Iowa. 1982. Iowa Geological Survey Open-File Report OFGR 82-3. Available from: http://s-iihr34.iihr.uiowa. edu/publications/uploads/2014-09-12 15-09-59 ofr $\% 2082-3$.pdf.

Lorena. 2010 July 8. Coyotes, groundhogs chewing lights at Iowa airport. Associated Press. Available from: http://aviaed.wordpress.com/2010/07/08/ coyotes-groundhogs-chewing-lights-at-iowaairport/.

O’Connor KM, Dowding CH. 1999. GeoMeasurements by pulsing TDR cables and probes. Boca Raton (FL): CRC Press.

Tektronix, Inc. 1989. 1502B metallic time domain reflectometer operator manual. Redmond (OR). 
